\title{
Requirement of Young Carp for Vitamin A
}

\author{
Hiroshi Aoe, Isao Masuda, Tsuguo Mimura, Takashi SaIto, \\ and Atuko Komo* \\ (Received August 5, 1968)
}

The requirement of salmonoid fishes for vitamin $\mathrm{A}$ and their deficiency symptoms have been studied and fairly well-defined by the Japanese and American workers ${ }^{1-57}$. Knowledge on carp, Cyprinus carpio, is still lacking. Although a few papers ${ }^{8,7}$ dealing with the growth-promoting effect of cod-liver oil on carp are available, they were based on nutritionally defective test diets.

Succeeding to the previous works on water-soluble vitamins, the role of vitamin $A$ in nutrition of young carp was examined by using synthetic vitamin $A$ and the test diet devised by HALVER et al, ${ }^{\text {, }}$ Elimination of vitamin A from the diet caused the typical deficiency symptoms, characterized by anorexia, retarded growth, faded body color, hemorrhage in the fins and skin, warped gill opercula, and exophthalmia.

The present paper deals with these deficiency symptoms and requirement of young carp for vitamin A.

\section{Experimental and Results}

Diet and feeding method. The composition of basal diet and feeding method were the same as those described in the previous paperil on vitamin $B_{2}$. Soy-bean oil used was ascertained to be free from vitamin $A$ and served as a vehicle for vitamin A supplemented to the test diets. The preparation used was synthetic vitamin $A$ acetate in all-trans form.

Determination of vitamin A. The vitamin A concentration of diet and experi. mental fish was determined by the usual Carr-Price method ${ }^{10 \%}$. Fish were analyzed only on the hepatopancreas and the values are expressed by I. U. per $\mathrm{g}$ on wet basis.

A preliminary test on requirement for vitamin A. To see the approximate level of requirement and deficiency symptoms, young carp were kept on diets containing different quantities of the vitamin, 10,30,100,400,2,000, and 10,000 I. U. per $100 \mathrm{~g}$ of diet, respectively. In the diet vitamin $\mathrm{A}$ was kept unchanged in a freezer at least for one week, until the diet was renewed.

After being fed preliminarily on the diet containing $2,000 \mathrm{I}$. U. per $100 \mathrm{~g}$ for 2 weeks, young carp weighing $2.2 \mathrm{~g}$ in average were divided into 7 groups of each 30 fish (Groups 1 to 7), and reared for 16 weeks from December 6, 1966 to March 27, 1967. At the end of 8th week, the number of fish was reduced to 20 in each group

* Central Laboratory of Nisshin Flour Milling Co., 177, Tsurugaoka, Ohi, Irumagun, Saitama

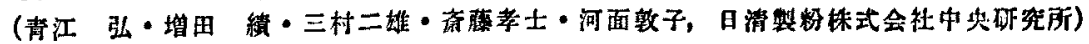


Table 1. Results of the preliminary experiment on requirement for vitamin A.

\begin{tabular}{|c|c|c|c|c|c|c|c|c|}
\hline \multirow{3}{*}{$\begin{array}{c}\text { Group } \\
\text { No. }\end{array}$} & \multirow{3}{*}{$\begin{array}{l}\text { Vitamin } \mathrm{A} \\
\text { added } \\
\text { I.U. } / 100 \mathrm{~g}\end{array}$} & \multirow{3}{*}{$\begin{array}{l}\text { ortality } \\
\text { \% }\end{array}$} & \multirow{2}{*}{\multicolumn{2}{|c|}{$\begin{array}{l}\text { Average body } \\
\text { weight* at the end } \\
\text { of feeding period } \\
\text { in weeks }\end{array}$}} & \multirow{2}{*}{\multicolumn{2}{|c|}{$\frac{\text { Feed conversion \% }}{\begin{array}{c}\text { Feeding interval } \\
\text { in weeks }\end{array}}$}} & \multirow{2}{*}{\multicolumn{2}{|c|}{$\begin{array}{l}\text { Vitamin A } \\
\text { concentration in the } \\
\text { hepatopancreas } \\
\text { I.U./g on wet basis }\end{array}$}} \\
\hline & & & & & & & & \\
\hline & & & 8 & 16 & $0 \sim 8$ & $8 \sim 16$ & 8th week & 16 th week \\
\hline 1 & 0 & 5 & 14.5 & 50.3 & 125.5 & 100.7 & 1.3 & 2.1 \\
\hline 2 & 10 & 3.3 & 15.3 & 53.2 & 136.0 & 103.6 & 4.3 & - \\
\hline 3 & 30 & 3.3 & 15.6 & 60.6 & 134.1 & 109.2 & 12.5 & 1.9 \\
\hline 4 & 100 & 3.3 & 15.1 & 58.4 & 128.3 & 107.1 & 3.8 & 3.1 \\
\hline 5 & 400 & 0 & 15.5 & 61.4 & 135.0 & 110.9 & 2.7 & 2.2 \\
\hline 6 & 2,000 & 0 & 15.6 & 65.0 & 137.8 & 119.1 & 27.1 & 24.8 \\
\hline 7 & 10,000 & 0 & 15.0 & 60.4 & 130.5 & 109.9 & 223.5 & 364.5 \\
\hline
\end{tabular}

* The initial weight: $2.2 \mathrm{~g}$ in average.

and the remainder of fish was used for determination of vitamin A. The increase of average body weight and feed conversion are shown in Table 1. Loss of a few fish each in Groups I to 4 was due to accidents.

In the first half of experimental period, fish exhibited a good appetite and normal
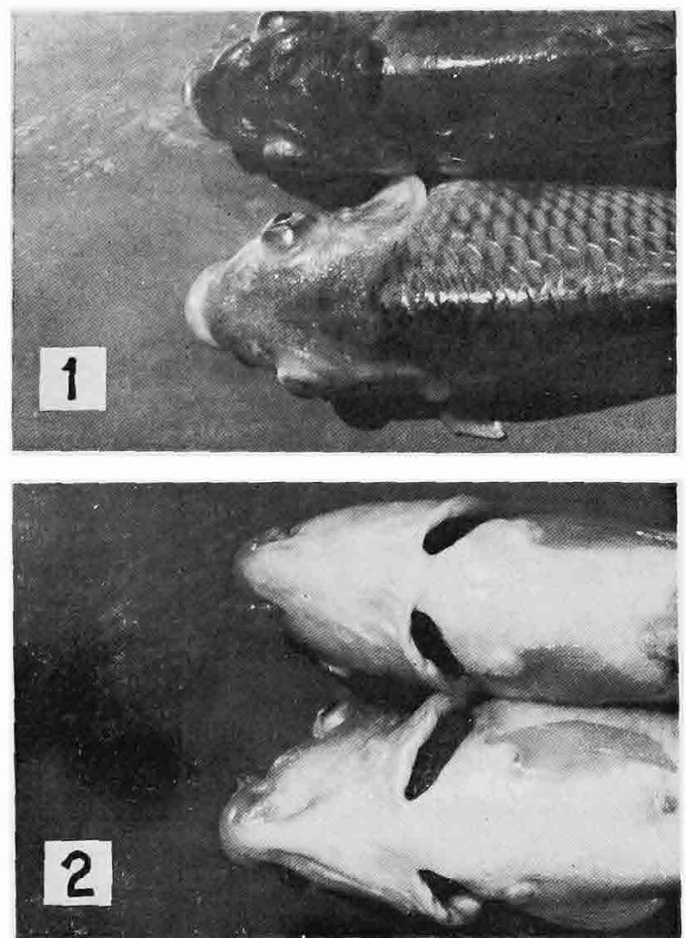

Fig 1. Carp exhibiting warped gill opercula and exophthalmia. growth, except those in Group 1 which showed a slightly lower increase in average body weight. In the last half, however, fish in Groups 1 and 2 showed anorexia and consequently decrease in average body weight. In addition, fish in Groups 1 to 4 demonstrated the deficiency symptoms, such as faded body color, hemorrhage in the fins and skin, warped gill opercula, and exophthalmia as shown in Fig. 1. The number of abnormal fish at the final stage were $13,19,12$, and 15 in Groups 1 to 4 , respectively.

A recovery lest. At the end of the 16 th week, 20 fish in Group 2 were divided into halves for recovery test, and the one group (Group 8) was kept on the same diet as before, and the other (Group 9) on the diet containing $2,000 \mathrm{I}$. U. per $100 \mathrm{~g}$. The fish were at start 57.8 and $57.9 \mathrm{~g}$ in average 
body weight respectively, and kept for 13 weeks from April 6, 1967, since they recovered very slowly, differing from those deficient in water-soluble vitamin, which recovered completely in a period as short as 2 to 4 weeks. The increase in average body weight is shown in Fig. 2. The feed conversion of the both groups was 54.7 and $76.1 \%$, respectively. Four fish in Group 8 died on the 13th week, although all the fish in Group 9 survived and showed normal growth. Some of symptoms, such as warped gill opercula, hemorrhage in the fins and skin, and exophthalmia, however, did not disappear from the fish in Group 9 even by the end of the 13th week.

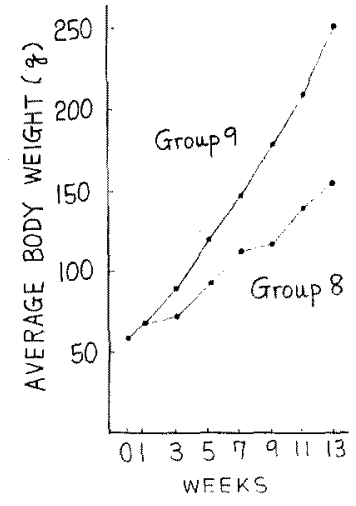

Fig. 2. Change of average body weight in the recovery test.

Vitamin A concentration of the hepatopancreas.

Carp in Groups 1 to 7 were analyzed for vitamin $\mathrm{A}$ at the end of the 8th and 16th week. As shown in Table 1, no appreciable difference is recognized in the vitamin concentration among fish in Groups 1 to 5 , but in those of Groups 6 and 7 the accumulation of vitamin is apparent.

Table 2. Results of the repeated experiment on requirement for vitamin $A$.

\begin{tabular}{c|c|c|c|c|c}
\hline Group No. & $\begin{array}{c}\text { Vitamin A } \\
\text { added } \\
\text { I. U./100 g }\end{array}$ & $\begin{array}{c}\text { Vitamin A } \\
\text { intake } \\
\text { I. U./kg body } \\
\text { weight/day }\end{array}$ & $\begin{array}{c}\text { Mortality } \\
\%\end{array}$ & $\begin{array}{c}\text { Feed } \\
\text { conversion } \\
\%\end{array}$ & $\begin{array}{c}\text { Vitamin A con- } \\
\text { centration in the } \\
\text { hepatopancreas } \\
\text { I.U./g on wet basis }\end{array}$ \\
\hline 10 & 0 & 0 & 0 & 83.6 & 1.2 \\
11 & 100 & 22.1 & 0 & 92.8 & 0.6 \\
12 & 200 & 43.8 & 0 & 97.2 & 2.1 \\
13 & 400 & 84.0 & 3.3 & 104.9 & 2.1 \\
14 & 2,000 & 448.0 & 0 & 93.2 & 206.4 \\
\hline
\end{tabular}

At the end of the recovery test, the values were 1.2 I. U. in Group 8 and 261.9 I. U. in Group 9 , respectively.

Estimation on requirement for vitamin $A$. To decide the requirement and deficiency symptoms more exactly, a similar experiment was carried out at levels, $0,100,200,400$, and 2,000 I. U. per $100 \mathrm{~g}$ (Groups 10 to 14). Five groups of each 30 fish weighing $3.4 \mathrm{~g}$ in average were placed in troughs for 16 weeks from May 12, 1967 . The results are shown in Table 2 and Fig. 3.

In Group 10, fish receiving the vitamin-free

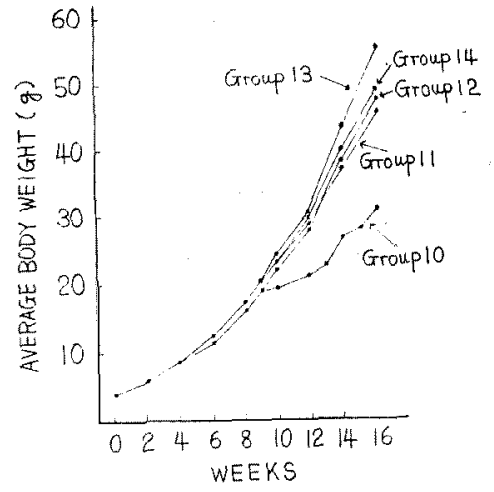

Fig. 3. Effect of vitamin A on the growth of young carp. 
Table 3. Frequencies of deficiency symptoms.

\begin{tabular}{c|c|c|c|c}
\hline Group No. & $\begin{array}{c}\text { Warped gill } \\
\text { opercula }\end{array}$ & Exophthalmia & Hemorrhage & $\begin{array}{c}\text { Number of abnormal } \\
\text { fish/normal fish }\end{array}$ \\
\hline 10 & 3 & & 13 & $16 / 30$ \\
11 & 25 & 7 & 17 & $29 / 30$ \\
12 & 9 & 12 & $19 / 30$ \\
13 & 2 & & & $2 / 29$ \\
14 & & & $0 / 30$ \\
\hline
\end{tabular}

diet began to exhibit a slightly poor appetite on the 4th week and faded body color on the 5 th week. Hemorrhage of the skin appeared on the 7 th week and expanded from the portion of fin to the whole body on the 9th week. These syndromes became obvious also in Group 11 at the same time. On the 12th week, warped gill opercula were recognized in Groups 10 to 13 , although such abnormality was only slight in the last group. On the 15th week, seven fish in Group 11 showed exophthalmia. Frequencies of each symptoms at the end of experiment are summarized in Table 3.

Besides these symptoms, the skin of deficient fish was found to be very sensitive to mechanical stimuli, and hemorrhage rapidly appeared when the fish were handled with a net or wiped with gauze on their body. Although the erythrocyte number was not determined, there was a sign of anemia. The deficient fish were much more sensitive for the shortage of dissolved oxygen than the normal fish, when the water supply was stopped by accident.

In histological investigation the gill lamellae were confirmed to have fused each other and to be clubbed at the tips in the deficient fish of Group 10, as shown in Fig. 4.

Each five fish in Groups 10 to 14 were analyzed for vitamin A in the hepatopancreas at the end of the 16th week. The values on wet basis are shown in Table 2. The value for Group 14 was higher than that for the corresponding Group 6 .

As shown in Table 2 and Fig. 3 , it is difficult to decide exactly the requirement for vitamin A from the body weight gain, differing the cases of water-soluble vitamins. From the deficiency symptoms and vitamin A concentration in the hepatopancreas, the requirement was roughly estimated to be $400 \sim 2,000 \mathrm{I}$. U. per $100 \mathrm{~g}$ of diet, or $100 \sim 500 \mathrm{I}$. U. per $\mathrm{kg}$ of body weight per day, under the experimental conditions adopted.

\section{Discussion}

The deficiency symptoms of vitamin A in young carp were described in detail for the first time. They were essentially identical with those reported on rainbow trout by KITAMURA et al. ${ }^{45}$ In salmonoid fish, all the symptoms other than warped 


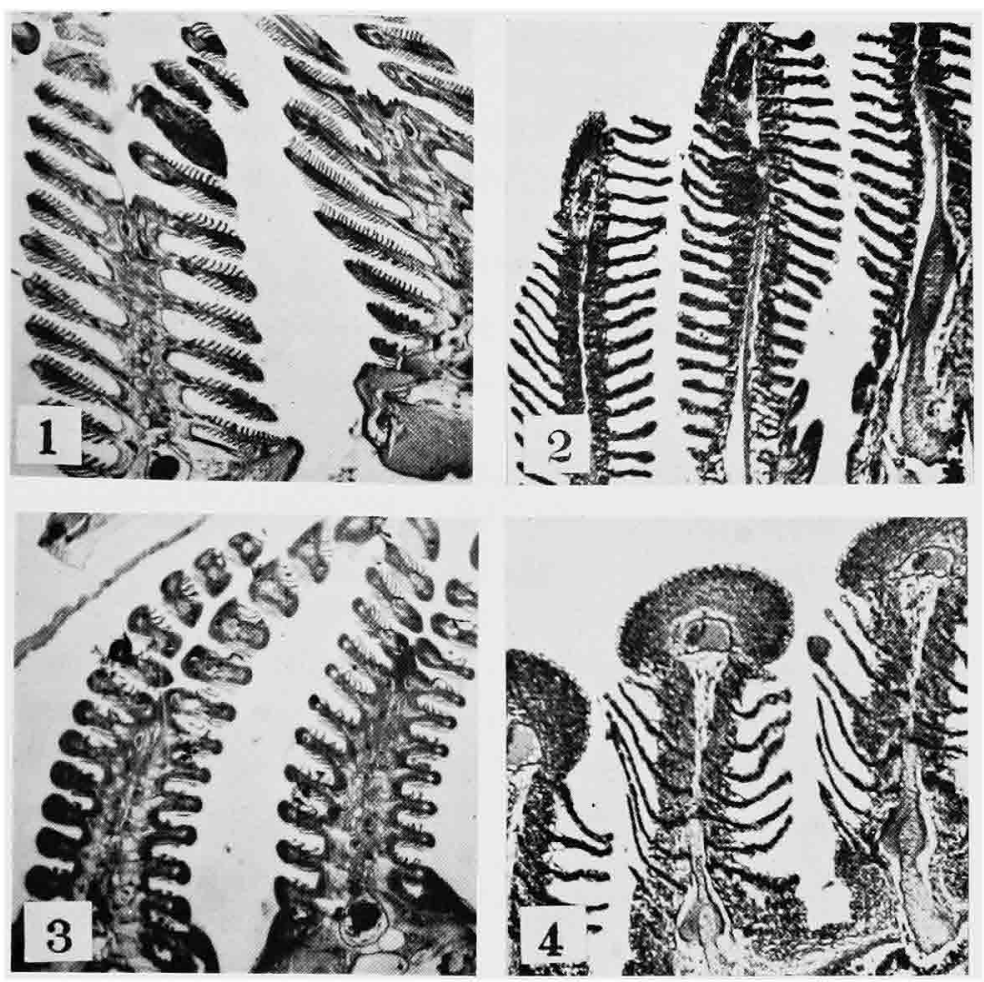

Fig. 4. Gills of normal and vitamin A-deficient carp.

1. Normal carp $(\times 28)$.

2. $"(\times 70)$.

3. Vitamin A-deficient carp $(\times 28)$.

4. " $(\times 70)$.

gill opercula were found to recover on administration of vitamin A, whereas in carp hemorrhage and exophthalmia remained as sequelae besides warped opercula.

Dietary gill disease was reported on salmonoid fish by a few workers as one of the deficiency symptoms of pantothenic $\operatorname{acid}^{1,11 \sim 13)}$. It is interesting that in carp the similar symptom occurred as the result of vitamin A deficiency.

$\mathrm{HoNJO}^{3)}$ gave a value, $1,000 \mathrm{I}$. U. as the requirement of rainbow trout per $\mathrm{kg}$ of body weight per day, by estimating storage of vitamin $\mathrm{A}$ in the various organs of fish receiving cod liver oil as a vitamin source. On the other hand, Kitamura et al. ${ }^{5}$ ) estimated the requirement of rainbow trout fingerling per $100 \mathrm{~g}$ of diet devised by HALver et al. to be more than $250 \mathrm{I}$. U. on the basis of body weight gain. The value obtained on carp in the present study is lower than that reported by HoNJo, but fairly higher than that by KITAMURA.

It is a well-known fact $^{14)}$ that fresh-water fishes contain vitamin $A_{2}$ besides $A_{1}$. In the present study, it was confirmed at least that the lack of vitamin $A_{1}$ induces the deficiency symptoms in carp which is alleviated by addition of vitamin $A_{1}$. The 
analytical values given in the present paper on vitamin $A$, however, should contain some uncertainty depending on the relative proportion of vitamin $A_{z}$ in the hepatopancreas. To understand the role of vitamin $A$ in nutrition of carp, a further study may be necessary, especially on the nutritive value of vitamin $A_{2}$.

\section{Summary}

1. The deficiency symptoms and requirement for vitamin $A$ of young carp have been studied, using the synthetic vitamin $A$ acetate and the basal diet devised by HALVER et al.

2. The deficiency symptoms were characterized by anorexia, retarded growth, faded body color, hemorrhage in the fins and skin, warped gill opercula, and exophthalmia. These symptoms could not be alleviated by administration of vitamin A, except anorexia, retarded growth, and faded body color.

3. Under the experimental conditions adopted, the requirement of young carp was estimated to be $400 \sim 2,000 \mathrm{I}$. U. per $100 \mathrm{~g}$ of diet, or $100 \sim 500 \mathrm{I}$. U. per $\mathrm{kg}$ of body weight per day, on the basis of the deficiency symptoms and vitamin A concentration of the hepatopancreas.

\section{Acknowledgement}

The present authors wish to express their sincere thanks to Prof. Y. Hashimoto, University of Tokyo, for his kind advice.

\section{References}

1) B. A. Mclaren, E. Keller, D. J. O'Donneli, and C. A. Elvehjem: Arch. Biochem., 15, $169 \sim 178$ (1947).

2) A. M. Phillips, Jr. and D. R. BRockway: Prog. Fish-Cult., 19, 119 123 (1957).

3) T. Honjo: The Aquiculture (Japanese), 13, 15 21 (1965).

4) S. Kitamura, T. SUwa, S. Ohara, and K. NaKaGawa: This Bull., 33, 1120 1125 (1967).

5) S. Kitamura, T. SuWa, S. Ohara, and K. NaKaGaWa: This Bull., 33, 1126 1131 (1967).

6) K. Matsui and N. OShima: Suisan Shikenjo Hokoku, 6, 202 218 (1935).

7) S. Ueno, K. Ohta, K. Tone, and S. Yokoyama: Kogyo Kagaku Zasshi, 35, 1233 1235 (1932).

8) J.E. Halver and J. A. Coates: Prog. Fish-Cult., 19, 112 118 (1957).

9) H. Aoe, I. Masuda, T. Saito, and A. Komo: This Bull., 33, $355 \sim 360$ (1967).

10) The Association of Vitamin Chemists Inc.: Methods of Vitamin Assay, 2nd ed., 301 pp. Interscience Publishers, Inc., New York, (1951).

11) L.E. Wolf: Fisheries Research Bull. No. 7 (1945).

12) J. E. Halver: J. Nutrition, 62, $225 \sim 243$ (1957).

13) E. M. Wood and W. T. YAsutake: Prog. Fish.Cult., 19, 7 13 (1957).

14) G. Borgstrom: Fish as Food I, Academic Press, New York and London (1961). 